would seem that, among other things, Boccaccio is underlining the inherent ambiguities of the text and the necessity of interpretation, while perhaps poking fun at our attempts to fix truth in a text when even the status of the Sacred Scriptures, Boccaccio implies, depends on how they are interpreted.

Forni's digression in the first part of the fourth chapter, in which he discusses his theme of the "poetics of realization" in terms of the stories of the twentieth-century author, Massimo Bontempelli, turns out to be particularly interesting. Here Forni addresses the risks and ultimate entertainment value of understanding metaphors iiterally. One of the examples the author gives is Bontempelli's Il buon vento in which the protagonist, Massimo, discovers a magic powder that effectively connects the physical and spiritual worlds. Thus when other characters in the story tell Massimo that their hearts bleed for him or that they have a word on the tip of their tongues, they really do, much to Massimo's initial surprise. Work by theorists on the literature of the fantastic (T. Todorov, N. Bonifazi, C. Brooke-Rose, et al.) serves as a point of departure for Forni's discussion of the Decameron's own literalizations of metaphors, including the scraping of Peronella's tub (7.2), and the lending of mortar and pestle by Belcolore and the sacristan (8.2).

"The testing and forcing of rhetorical boundaries between sententia and eventum is a recurring aspect of Boccaccio's inventio," Forni concludes (114). But this point of adventus is rather less adventurous than the title of the study suggests. Unfortunately, the emphasis on the analysis of rhetorical forms in Boccaccio's prose effectively relegates hermeneutics and aesthetics to a peripheral domain. The reader of Adventures does not have the sense - as a reader of the Decameron would - that Boccaccio's venture has its substance in an exploration of the relationship between pleasure and narration, the play and frustrated potentiality in representation, and the crucial role of interpretation that Boccaccio rigorously demands of his narrators and their stories' protagonists, and even of himself, to say nothing of his public.

Readers familiar with Forni's previous studies on Boccaccio, especially Forme complesse nel Decameron (Firenze: Olschki, 1992), will find in Adventures the further development of previous arguments. The very frequency, however, with which the author must make a variation on the statement that he is presenting here a "substantial addition of new evidence" $(\mathrm{x})$ almost begs the reader to doubt him. Nevertheless, the book, which is a welcome addition to the University of Pennsylvania Press Middle Ages Series, presents an eloquent and concise treatment of a Boccaccian realism, no longer the outcome of ideology, but as the realization of the rhetorical imagination.

\title{
SHERRY ROUSH
}

Yale University

Olga Zorzi Pugliese. Il discorso labirintico del dialogo rinascimentale. Roma: Bulzoni, 1995. Pp. 143.

We are fascinated by dialogue. As the number of Internet hosts doubles almost every year, more and more people are thinking about dialogue, and calling for it. The ques- 
tion is, do we understand what dialogue is? Can we distinguish authentic dialogue from gossip or dressed-up monologue? The obvious place to look for a sustained discussion of dialogue is the rich tradition of literary dialogue stretching back to Plato and the surrounding criticism. For this reason works like Olga Pugliese's $I l$ discorso labirintico del dialogo rinascimentale are relevant not just to those interested in the Italian Renaissance dialogue, but also to those interested in understanding the possibilities (and limitations) for dialogue in general.

The problem with understanding dialogue is that with the growing fascination it has become a concept with which we try to understand all discourse rather than a particular type of discourse. There is no longer a clear sense of what works or activities can be called a dialogue, because theorists like Buber and Bakhtin have transformed dialogue into a characteristic of all discourse. Dialogue is no longer a technical term for a genre of literary-philosophical text, it is paradigm against which we now compare all texts, all human interaction, and even the interaction between humans and other entities, for example when we talk about human-computer dialogue, or Marxist-Christian dialogue.

The problem is only made worse by the unexamined consensus that dialogue is generally a good thing. To find the dialogical in an event or work is to praise it. This positive connotation that sticks to dialogue today combined with the interpretative openness to the dialogical in any interaction leads to an inflationary tendency to promote suspect cases and causes by stretching the mantle of dialogue to cover them. How often are complex issues distracted by errant calls for dialogue which no one has the courage to silence because to refuse dialogue is the last $\sin$ in the postmodern world? How often are the most straightforward texts interpreted into meaninglessness by the discovery of the dialogical lurking under the hood. To understand the place of dialogue we need a better sense of what is at stake, why dialogue proceeds in certain circumstances, and what we stand to lose when we choose it. This is where, as I will point out later, Pugliese offers a interesting opening.

These issues concern not only those interested in dialogue in general but also those, like Pugliese, who are interested in a particular period of literary dialogue such as the Italian Renaissance dialogue. To study the evolution of the genre over time one needs a theoretical framework that both allows one to unpack a particular dialogue and to compare dialogues over time. Often an interpretative framework that works well for discovering the dialogical in a work is not suited to distinguishing between dialogues or explaining the absence of dialogue. Likewise a definition of dialogue that is good for comparison may not suit for the fine reading of particular works. In choosing the labyrinthine as the interpretative tool with which to look at Renaissance dialogues, Pugliese has to balance the need for a tool that shows how particular dialogues work and the the demonstration of how over time the Renaissance dialogue ceased to be dialogical.

Pugliese's book on the labyrinthine discourse of the Renaissance dialogue is a useful contribution to what the humanities has to offer to this larger problem. While Pugliese is dealing in this work with problems with the interpretation of a particular period of literary dialogue, the concept of the labyrinth is applicable to dialogues from other eras and potentially useful for understanding types of dialogue that are not literary. Her short and clear work has two major parts. Close to half the book is taken up by one of the best introductions I have read to the interpretation of literary dialogues and 
to the fleshing out of her proposal, to which we will return shortly, that the concept of the labyrinth is a useful interpretative heuristic. This first and major chapter is a gem combining a survey of much of what has been written on the subject with a proposal based on one of the most intriguing of Renaissance theorists, Sperone Speroni. In the remaining three chapters she reads closely four dialogues that show the change in the Italian Renaissance dialogue from the open dialogues of the early Quattrocento to the linear ones that came later. These readings show the evolution of the Italian dialogue and illustrate the application of the labyrinthine heuristic proposed in the first chapter. In short the book introduces the reader to the interpretation of dialogue, proposes a labyrinthine heuristic, and then demonstrates this in the close reading of a representative set of dialogues in order to show the change in the form over time.

The interpretative heuristic that Pugliese proposes is the idea of the dialogue as a literary labyrinth. This is drawn from her reading of the 16 th century dialogue writer and literary theorist Speroni who, in his Apology for Dialogues (Apologia dei dialo$\mathrm{ghi}$ ), defends his youthful dialogues in a rambling response to accusations from the Inquisition. Pugliese nicely draws out of Speroni an image of the differences between dialogue and other genres as the difference between a labyrinth and straight road. The dialogue for Speroni is a wandering genre not a straightforward one. It is like a maze in which one errs from the direct path of the philosophical treatise in both the sense of often leaving what is apparently the topic and in the sense of introducing erroneous thoughts. The dialogue is defined by the way its treatment of its subject resembles more the pleasurable garden through which one can stroll than the straight pedestrian road one uses to get somewhere. If it were a type of terrain, the dialogue would be one where it is possible to wander in circles getting pleasurably lost rather than a utilitarian road traversed to get somewhere.

Speroni's defense of his dialogues is based on making a virtue out of what others considered their vice, the ambling character, the lack of conclusive positions, the inclusion of disreputable characters and the voicing of possibly erroneous views that might distract one from the path of virtue. These errant characters and crooked views are what make the work labyrinthine in that the reader has to contend with arguments that wander off topic and away from the accepted truths rather than going straight to the orthodox point. Pugliese nicely points out how this labyrinthine metaphor for dialogue reversed the conventional connotations of the labyrinth as the tortuous terrain of temptation and error. Speroni's defense, rather than deny that his dialogues err, is to make deviation the virtue of dialogue - to define dialogue as a genre characterized by pleasurably errant argument. By defining dialogue in such a way he makes his dialogues typical of the genre and therefore, by definition, acceptable because they are dialogues. Speroni, as Pugliese points out, introduces the labyrinth as a metaliterary device for understanding a genre (and therefore understanding the innocence of his examples of this genre) not as it had been used as an image for temptation, error, and disorientation. By repurposing this image he can turn its associations so as to justify his use of dialogue. If dialogues should be labyrinths, and labyrinths enclose errant paths, then it is proper for a particular dialogue to include errant views.

Pugliese after describing this ingenious apology for dialogue, proposes that it can be used as a heuristic for interpreting dialogue. In the section on Bruni's Dialogi ad Petrum Paulum Histrum she shows how the movement of the characters back and forth across Florence reflects a movement of the argument back and forth. The labyrin- 
thine character of the dialogue can be seen in the transitions and passages both in the dramatic movement of the dialogue and in the course of the discussion where the central character argues both sides of the question. Then in the section on Valla's $D e$ professione religiosorum Pugliese shows how the lack of clear indications as to the author's beliefs can lead to a labyrinthine ambiguity. With both of these Pugliese shows the value of paying attention, when interpreting a dialogue, to the ways in which it is not straightforward in its exposition. The proof, if you will, of her heuristic is in its use in the interpretation of these two dialogues.

Pugliese also uses 'labyrinthicity' as a metric against which to measure the degree to which a work is dialogical. There is generally a consensus that something happened to the Italian dialogue between the Quattrocento and Seicento - that the earlier dialogues were more vibrant and better examples of the genre. Virginia Cox in The Renaissance Dialogue: Literary Dialogue in its Social and Political Contexls, Castiglione to Galileo (1992), describes the change as a closing of the dialogue due to the increasingly oppressive literary climate in Italy. Pugliese offers 'labyrinthicity' as an alternative, (and in my opinion better), way to measure the slow decline from the dialogues of Bruni and Valla, through the transitional one of Bembo, to the linear work of Della Casa. (While Cox is fascinating on the political and social context of this shift, I think Pugliese offers a more useful hermeneutical tool for other periods of dialogue with different social conditions.) She goes so far as to conclude the book by suggesting that Della Casa's Galateo, while technically a dialogue in the sense of a representation of a conversation, is "anti-dialogical" in its suppression of other voices, erring ways, and alternative arguments.

If Pugliese's interpretative chapters have a problem it is that she does not spend enough time connecting her careful discussion of a particular dialogue to her central thesis about the labyrinthine character of dialogue in general. These chapters are good enough that they could stand alone without the discussion of 'labyrinthicity' and therefore they leave me with the feeling that the idea of the labyrinth rather than driving the interpretations was an afterthought to connect them. To be fair to Dr. Pugliese, there is bound to be a tension in a work like this between close attention to the text at hand and using it to exemplify a hermeneutical position. That said, I look forward to more help understanding exactly how to read for the labyrinthine and expect that as Pugliese develops this idea in other works we will see more clearly how it can be applied to other periods of dialogue and other types of dialogue.

At this point we can speculate about the strengths and weaknesses of Pugliese's interpretative suggestion. The major problem with scaling Speroni's defense out into an interpretative framework is that Speroni's labyrinth is an image of dialogue, not a definition. It is difficult to get a precise definition from an analogy. While the image (along with all the others Speroni offers up in his garden) might suit when defending one's own dialogue from the Inquisition, one needs something more rigorous if one wants to study the history of dialogue. For this reason Pugliese offers it to us as a heuristic not as a definition of dialogue. The labyrinth can be used as a unifying image that brings together many of the subtler features of successful dialogues which we should be looking for in different forms in any particular dialogue that we choose to read. We can also see how this suggestion is better suited to trying to assess the degree to which a work is dialogical than defining the superficial traits of the genre. This image of the cialogue does not generate measurable features that we could use to 
define dialogue, but it does give us a rich network of characteristics to look for when trying to appreciate a dialogue or understand how a work is anti-dialogical. As such it is a suggestion for the reading of dialogues that seems appropriate to dialogue, both because it came from Speroni, a writer of dialogue and an apology that is itself labyrinthine, but also because it is a complex image in which one can get lost, not a straightforward definition.

To conclude we can now speculate about Pugliese's solution to the larger problem I set out at the beginning of this review - how to understand dialogue in a way that shows what is at stake. One of the central features of the dialogue is its ability to encompass errant talk, whether it be digressions or potentially erroneous views. It is this willingness to err that distinguishes the authentic dialogue, but with this willingness comes the loss of certainty which comes with the introduction of digressions, distractions, and errant views. The dialogue that does not err and tries to get to the point, while clearer and better at the presentation of a single coherent thesis, would not be dialogical. We can all think of unsuccessful dialogues like Plato's Laws, where the presentation of a single view overwhelms the dialogue rendering it a dialogue in name only. By contrast, the dialogues we find most pleasant are those where we cannot with certainty say what the author's position is and when we try to do so we find ourselves wandering through a maze of interpretations. The dialogue form encourages, through the juxtaposition of characters and ideas, an uncertainty that frustrates the straightforward interpretation forcing the reader into a labyrinth of considerations. Pugliese's work does not lead us out of this maze, but shows how we might appreciate it for what it is and trace the contours of the labyrinth.

\section{GEOFFREY ROCKWELL}

McMasler Universily

Jackson I. Cope. Secret Sharers in Italian Comedy: From Machiavelli to Goldoni. Durham and London: Duke University Press, 1996. Pp. x, 221.

Il nome di Jackson I. Cope è ben noto agli studiosi del teatro italiano del Rinascimento, che hanno già avuto modo di apprezzare la vivacità delle sue intuizioni e l'impegno delle sue ricerche in lavori quali The Theater and the Dream: From Metaphor to Form in Renaissance Drama (Baltimore and London: Johns Hopkins UP, 1973) e Dramaturgy and the Daemonic: Studies in Anti-Generic Theater from Ruzante to Grimaldi (Baltimore and London: Johns Hopkins UP, 1984). In questa nuova opera il critico analizza una serie di testi più o meno noti partendo da una angolatura particolare: mentre nella struttura della Commedia Nuova di Plauto si assiste a un conflitto tra generazioni che si conclude con una rinnovata armonia fra i vecchi e i giovani (una struttura che si riflette nei testi a stampa della Commedia dell'Arte e in numerose occasioni della Commedia Erudita), nel corso del Rinascimento emerge quasi un sotto-genere di questa formula, il quale, pur conservando le componenti fondamentali dell'altro, presenta la circostanza in cui, nell'apparente rappacificazione finale, alcuni personaggi restano all'oscuro di qualcosa che è noto invece ad altri e al pubblico stesso. In tale prospettiva l'analisi si orienta ad approfondire in quei testi 